\title{
Successful total correction of congenital interruption of the aortic arch and ventricular septal defect
}

\author{
M. P. SINGH, H. H. BENTALL, and C. M. OAKLEY \\ Departments of Cardiothoracic Surgery and Clinical Cardiology, Royal Postgraduate Medical School and \\ Hammersmith Hospital, London, W.12
}

\begin{abstract}
Successful surgical correction of the complex anomaly of interruption of the aortic arch and intracardiac ventricular septal defect is reported. The patient was a boy 5 years old when he first came under treatment. The total correction was performed in two stages. At the first operation, at the age of 7 years, continuity of the aortic arch was achieved by insertion of a Teflon graft, employing left heart bypass. The ventricular septal defect was closed at the age of 13 years on total cardiopulmonary bypass. Two and half years after the total correction the boy is alive and well. The difficulties in diagnosing the condition are discussed. The role of left heart bypass is emphasized.
\end{abstract}

The condition of interruption of the aortic arch was first described by Steidele in the late eighteenth century (1777-88). This is a rare (Evans, 1933) and complex congenital anomaly in which a segment of the aortic arch is absent (Fig. 1). In addition, the combination of a patent ductus arteriosus with intracardiac anomalies is almost invariably present. The patent ductus arteriosus is nearly always large and continuous with the descending aorta. The descending aorta is thus seen as a continuation of the main pulmonary artery through the duct which completes the arch.

In true interruption of the aortic arch the proximal and distal aortic segments are widely separated. When the two segments are joined by a fibrous strand the term atresia is applied. Other synonyms such as stenosis and hypoplasia have also been used (Moller and Edwards, 1965).

The proximal aorta is underdeveloped and divides into the innominate and the left common carotid arteries. The left subclavian artery may
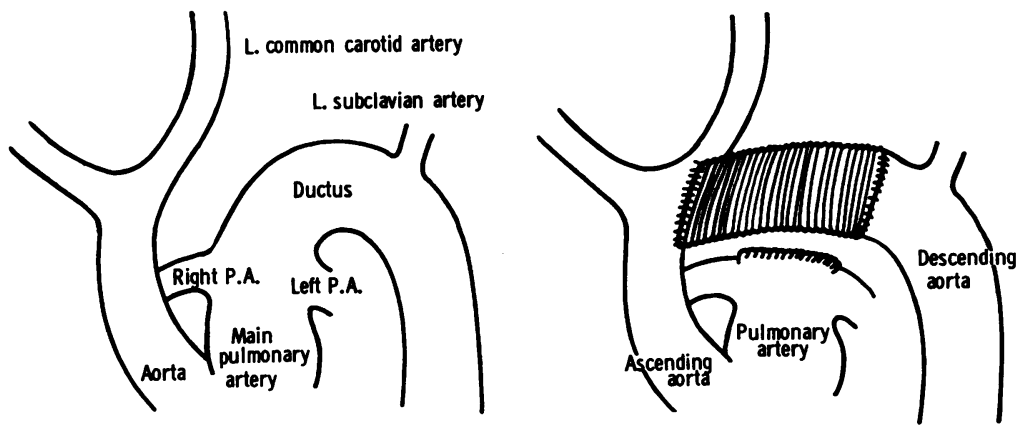

FIG. 1. Left: The anatomy of the great arteries before surgery. The ascending aorta is small and divides into two branches, the innominate and the left common carotid arteries. The main pulmonary artery is very large and, after giving off the branches to the left and right lung, the vessel continues into an arch formed by the ductus arteriosus and its junction with the descending aorta, from which the left subclavian artery arises.

Right: The anatomy of the great arteries after the first operation. The ductus has been divided. An aortic arch has been formed by a Teflon graft which bridges the gap between the ascending and descending aorta. 
arise from either the proximal or the descending aorta, depending on whether the interruption is distal or proximal to the left subclavian artery (Abbott, 1927). Rarely the interruption is situated between the innominate and the left common carotid arteries (Weisman and Kesten, 1948). Celoria and Patton (1959) designated the lesions into type $\mathrm{A}, \mathrm{B}$ or $\mathrm{C}$ respectively. Moller and Edwards (1965) described the anatomical patterns of interruption of the aortic arch and the associated intracardiac anomalies in a collected series of 105 cases. The commonest site of interruption was proximal to the left subclavian artery. The commonest intracardiac lesion was a ventricular septal defect either alone or as a part of complicated anomalies. There were only seven cases in which there was no ventricular septal defect and in two cases the patent ductus arteriosus was absent.

Roberts, Morrow, and Braunwald (1962) reviewed the literature, discussed the pathogenesis, and found that 51 out of 55 cases died within six months of birth. The diagnosis in most cases was made at necropsy.

Sporadic attempts at bridgement of the gap between the two segments of the aorta were reported by Merrill, Webster, and Samson (1957), Quie, Novick, Adams, Anderson, and Varco (1959), Ruiz Villalobos, de Balderrama, Lopez y Lopez, and Castellanos (1961), Blake, Manion, and Spencer (1962), Roberts et al. (1962), and Pillsbury, Lower, and Shumway (1964). Continuity between the proximal and distal aortic segments was established either by anastomosing a branch of one segment to the other or by inserting a prosthetic vascular graft between the two segments. To avoid any deleterious effect from aortic clamping, Roberts et al. (1962) advised closure of the patent ductus arteriosus only after establishment of continuity between the two aortic segments.

Sirak, Ressellat, Hosier, and deLorimier (1968) described construction of a tube from the left common carotid and the left subclavian arteries to provide a wide anastomotic channel.

Hairston, Webb, and Lee (1967) recommended palliative protection of the lungs from the overwhelming intracardiac left-to-right shunt by banding both branches of the pulmonary artery proximal to the patent ductus arteriosus.

Recently, Tawes, Panagopoulos, Aberdeen, Waterston, and Bonham-Carter (1969) reported end-to-end anastomosis in three cases among a number of surgical procedures in 11 cases.
Establishment of continuity of the aorta will be more readily achieved if collateral circulation is abundant and the distance between the two segments not too wide, as in atresia of the isthmus. However, collateral circulation may not be adequate and in interruption of the aortic arch the segments may be widely separated; then the surgeon is faced with a formidable problem.

We have corrected the complex anomaly of interruption of the aortic arch and ventricular septal defect in two stages in a boy who came under our care at the age of 5 years. The interruption of the aortic arch was bridged with a Teflon arterial graft using left heart bypass when he was 7 years old. The ventricular septal defect was closed at the age of 13 years using total cardiopulmonary bypass. $\mathrm{He}$ is alive and well, more than two and a half years after the second operation. The case is unique. It is described and the advantages of employing left heart bypass are discussed.

\section{CASE REPORT}

M. G., born on 30 July 1954, was admitted to the Hammersmith Hospital on 30 June 1959.

HISTORY OF PRESENT ILLNESS He was born after a normal delivery. His birth weight was $3 \cdot 17 \mathrm{~kg}$. A heart murmur was heard at the age of 1 month after he had been admitted to a fever hospital with gastroenteritis. He took feeds slowly and became breathless during the feeding. He gained weight poorly. Normal development was delayed.

His effort tolerance was very poor and he was severely disabled. He climbed stairs very slowly with much stopping and panting. He could walk only short distances and running would induce extreme dyspnoea. Because he could not skip and join other

T A B L E

CARDIAC CATHETER DATA

\begin{tabular}{|c|c|c|c|c|c|}
\hline & \multicolumn{5}{|c|}{ Year of Study } \\
\hline & 1955 & 1959 & 1961 & 1962 & 1967 \\
\hline Age (yr) & 1 & 5 & 7 & 8 & 12 \\
\hline $\begin{array}{l}\text { SVC } \\
\text { RA } \\
\text { RV } \\
\text { PA } \\
\text { LV } \\
\text { RBA } \\
\text { FA }\end{array}$ & $\begin{array}{c}59 \\
50 \\
77 \\
- \\
\overline{-} \\
\overline{75} \\
\begin{array}{c}\text { (Descending } \\
\text { aorta) }\end{array}\end{array}$ & $\begin{array}{c}59 \% \\
68-76 \\
84-91 \\
88 \\
= \\
88\end{array}$ & $\begin{array}{c}\text { Saturat } \\
74 \\
72 \\
78 \\
78 \\
75 \\
95 \\
80\end{array}$ & $\begin{array}{l}64 \\
65 \\
70 \\
75 \\
96 \\
96 \\
-\end{array}$ & $\begin{array}{c}51 \\
51-60 \\
89 \\
80 \\
98 \\
\end{array}$ \\
\hline Qp:Qs & $?$ & $4: 1$ & $\begin{array}{l}\text { Flows } \\
2: 1\end{array}$ & $1 \cdot 3: 1$ & $5: 1$ \\
\hline
\end{tabular}

RV and PA systolic pressures were equal to the systemic systopic pressure on every occasion that the $y$ were measured until the ventricular septal defect was closed. 


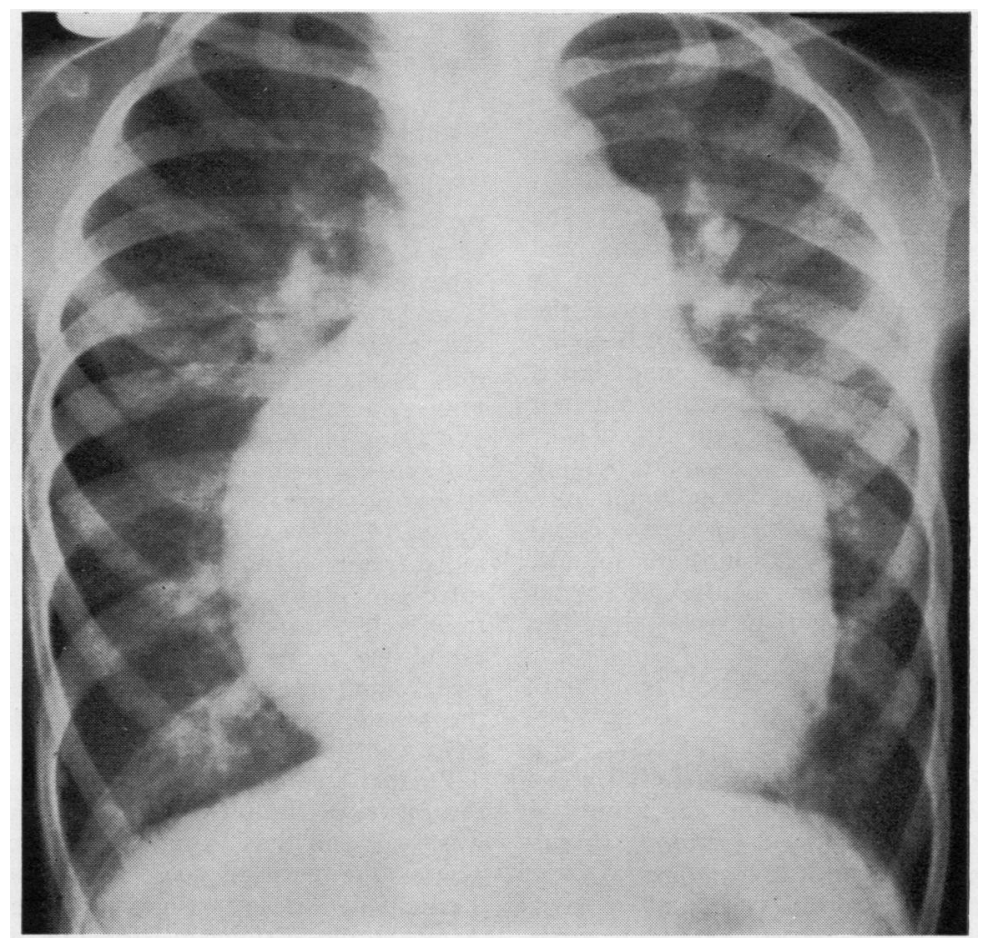

(a)

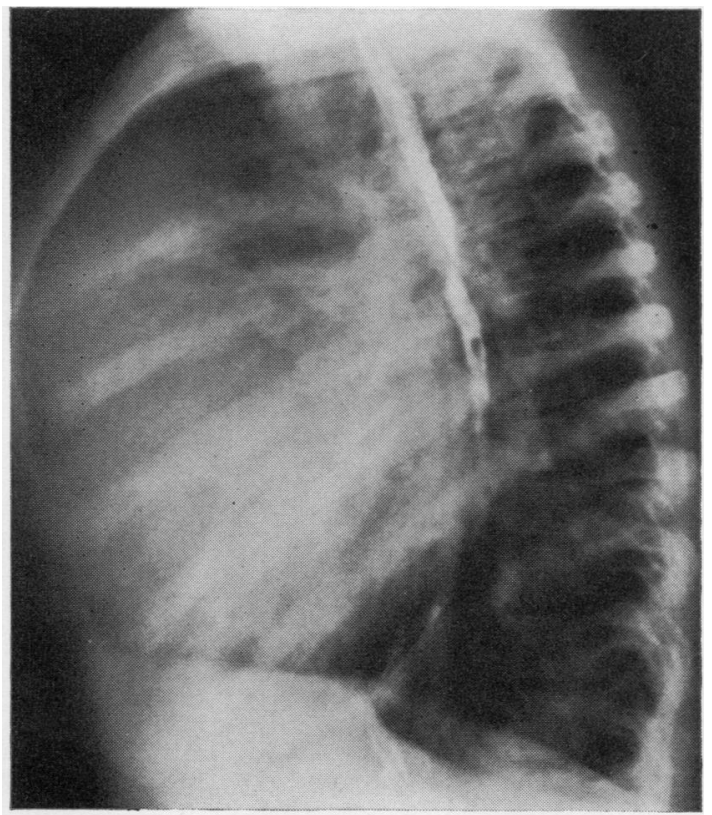

(b)
FIG. 2. (a) Chest radiograph in October 1961, before the first operation. The heart is very large. The 'aortic knuckle' is prominent but formed by the ductus. The pulmonary arteries and right atrium are particularly dilated. (b) The chest deformity seen on a lateral radiograph. The huge size of the right ventricular outflow tract and pulmonary arteries are also noteworthy.

children in play he would get upset and cried frequently. During dyspnoea and crying he developed cyanosis. His parents carried him around or pushed him in a pram. He frequently developed bronchitis during the winter, but of late this had persisted even in the summer.

PAST HISTORY He was seen at a Children's Hospital at the age of 1 year and cardiac catheterization was carried out (Table). Treatment with digoxin was started at the age of 18 months, but his mother discontinued it after three years as the treatment brought about no improvement.

FAMILY HISTORY His parents were alive and well. Two brothers, aged 18 and 13, were alive and well. 
Physical eXamination He was undersized. There was no cyanosis or differential cyanosis at the time of examination and there was no clubbing of the fingers or toes. Jugular venous pressure was $4 \mathrm{~cm}$. Blood pressure in the right arm was $105 / 75$, in the left arm 80/45, in the right leg 95/60, and in the left leg $95 / 60 \mathrm{~mm}$. Hg. The apex beat was in the fifth left intercostal space outside the midclavicular line. The praecordium was tumultuous with parasternal and apical heaves suggesting biventricular enlargement. A well-marked systolic thrill was palpable over the whole praecordium. Auscultation of the heart revealed accentuation of the pulmonary second sound and a nearly full-length grade $4 / 4$ mitral systolic murmur and a grade $2 / 4$ mid-diastolic murmur.

An increase in anterior sternal bowing and a bulging praecordium suggested stiff lungs from high pulmonary blood flow and pressure. Air entry was equal on both sides and there were no adventitious sounds.

The liver was enlarged $1 \mathrm{~cm}$. below the costal margin. There was no ascites and the veins over the abdomen were not prominent.

No abnormality was detected in the central nervous system.

INVESTIGATIONS Haemoglobin $14 \cdot 4 \quad$ g./100 $\mathrm{ml}$. Haematocrit $44 \%$, W.B.C. $8,000 /$ c.mm. and a normal pattern of differential count. Blood group $B$ rhesus positive. Ear oximetry: oxygen saturation at rest $96.5 \%$, oxygen saturation after two and a half minutes' exercise $55 \%$. A very large heart with particular dilatation of the right atrium and the pulmonary artery was seen in the chest radiograph (Fig. 2a and b). E.C.G.: Extreme left axis deviation (Fig. 3) suggested the possibility of either atrioventricular canal, multiple muscular septal defects or common ventricle.

TREATMENT The patient was digitalized and a maintenance dose of $0.125 \mathrm{mg}$. was continued.

In September 1959 he developed a right hemiparesis after cardiac catheterization. The hemiparesis gradually recovered, and cardiac catheter studies were repeated (Table). These studies demonstrated: (1) a large left-to-right shunt at ventricular and apparently also at atrial level; (2) a pulmonary flow of $12.51 . /$ min. and a systemic flow of 3.21 ./min., giving a pulmonary to systemic flow ratio of approximately $4: 1$; and (3) a pulmonary resistance of 6 units.

Angio-cardiography was technically unsatisfactory. It was not repeated because of the poor condition of the child. However, as attacks of bronchitis became more frequent and he was seldom free of respiratory infection, angio-cardiography and cardiac catheterization were undertaken in October 1961 in order to establish a more accurate diagnosis (Table). A left-toright shunt at ventricular level was confirmed and the ventricular septal defect was demonstrated by a right ventricular angiogram.

Further significant information was that the oxygen saturation of the blood from the right brachial artery was $94 \%$ and that from the left femoral artery $80 \%$. These findings were taken to indicate that there was a patent ductus arteriosus with 'reversal' of the shunt. A retrograde aortogram from the right femoral artery in December 1961 demonstrated a large patent ductus arteriosus and 'coarctation' of the aorta immediately

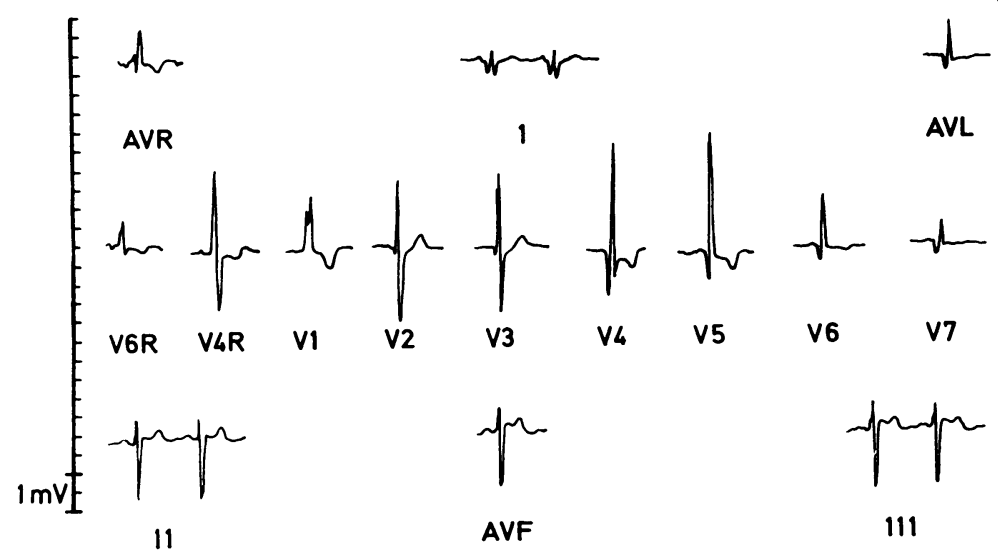

FIG. 3. Pre-operative electrocardiogram. There is abnormal deviation of the mean frontal $Q R S$ vector to the left and evidence of biventricular enlargement. The $Q$ waves visible in praecordial leads from V2 onwards suggest that the left ventricle occupies the praecordium and the heart was found to be rotated anti-clockwise around its vertical axis at operation. 
proximal to the left subclavian artery. It was decided to resect the 'coarctation' and to close the patent ductus arteriosus.

OPERATION I A left antero-lateral thoracotomy was performed on 14 February 1962 through the fourth intercostal space and later extended by transection of the sternum.

DEMONSTRATION OF THE ANATOMY (Fig. 1) There was complete interruption of the aortic arch. The ascending aorta was narrow $(0.5 \mathrm{~cm}$.) and bifurcated into the innominate and the left common carotid arteries. A wide patent ductus arteriosus, $1 \mathrm{~cm}$. in diameter, was continuous with the descending aorta. The left subclavian artery originated from the descending aorta. Digital palpation through the left atrial appendix revealed no atrial septal defect nor any abnormality of the mitral valve.

PROCEDURE A left heart bypass was instituted, from left atrium to left femoral artery. The patent ductus arteriosus was divided between clamps. The pulmonary artery was closed with $3(0)$ continuous arterial sutures. A Teflon arterial graft $(1.2 \mathrm{~cm}$. wide) was inserted between the ascending aorta and the cut end of the patent ductus arteriosus (Fig. 1). The ascending aorta was partially occluded and end-to-side anastomosis was made. The arterial graft was then passed through a tunnel made under the phrenic and the vagus nerves, and end-to-end anastomosis was completed between the graft and the cut distal end of the patent ductus arteriosus. The ventricular septal defect was not closed.

POST-OPERATIVE PERIOD This was rather stormy. Repeated endotracheal toilet was required. Heart failure was controlled with diuretics and digoxin. This treatment was continued indefinitely.

A retrograde aortogram on 22 October 1962, through the right femoral artery, demonstrated the arterial graft, but the catheter could not be passed through it into the ascending aorta.

There was no reduction in the cardiac size (Fig. 4). The boy showed little evidence of benefit from this operation and was reinvestigated. Reinvestigation on 27 April 1967 (Table) showed that the right ventricular and femoral artery pressures were both equal and inseparable. From this it was inferred that there was equality of the right ventricular, left ventricular, proximal, and distal aortic systolic pressures and therefore a large ventricular septal defect and an unobstructed aortic anastomosis.

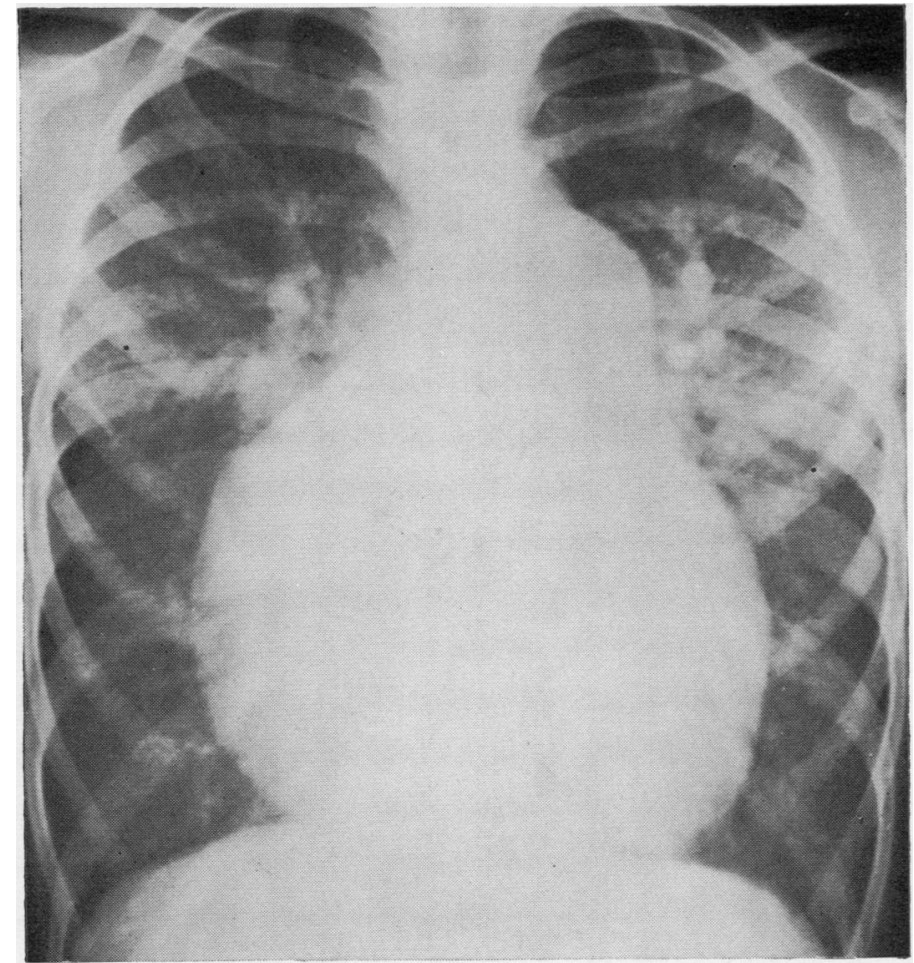

FIG. 4. Chest radiograph in August 1966, four years after the first operation. There has been little change in the cardiac configuration. 
The suggestion from the electrocardiogram that the defect was an atrioventricular canal was disproved: absence of atrial septal defect was shown by a great dissimilarity between left atrial and right atrial pressures together with failure to enter the left atrium with a catheter introduced from the saphenous vein. Absence of deformity of the left ventricular outflow tract was shown by angiography. A big infracristal ventricular septal defect was demonstrated. The oxygen step-up in the right atrium was therefore attributed to tricuspid incompetence. Mitral incompetence and tricuspid incompetence were present and thought to be consequent upon gross left and right ventricular volume overloading from the large leftto-right shunt.

As the defect was now realized to be operable, the child was readmitted on 14 July 1967 for closure of the ventricular septal defect.

OPERATION II On 20 July 1967 the heart was exposed through a median sternotomy. The ascending aorta was $2.5 \mathrm{~cm}$. in diameter. The pulmonary artery was huge, $6.0 \mathrm{~cm}$. in diameter. The heart was rotated anticlockwise. Total cardiopulmonary bypass was started. Moderate hypothermia with cooling to $30^{\circ} \mathrm{C}$. was used. The left ventricle was vented. Ventricular fibrillation was induced electrically. The aorta was not clamped. The right ventricle was opened through a transverse incision. A large ventricular septal defect, 4 by $4 \mathrm{~cm}$., was closed with a pericardial patch supported by Teflon felt and inserted with $2(\mathrm{O})$ interrupted silk sutures. The right ventriculotomy was closed. Air was removed from the left ventricle and the heart was defibrillated. There was no heart block. A marked reduction of the pressure in the right ventricle from systemic level to $24 \mathrm{~mm}$. $\mathrm{Hg}$ was observed.

POST-OPERATIVE PROGRESS Recovery was protracted as he tended to develop left ventricular failure, possibly due to the discrepancy between the enlarged left ventricle and the small aorta, which amounted to outflow obstruction of the left ventricle. This was treated with restriction of fluid intake and administration of diuretics and digoxin.

He also developed atrial fibrillation which was successfully converted on 4 September 1967, and the heart has remained in sinus rhythm since then.

PRESENT CONDITION It is now over two and a half years since the closure of the ventricular septal defect. Weight and height have increased markedly and there has been a steady reduction in heart size (Fig. 5). An

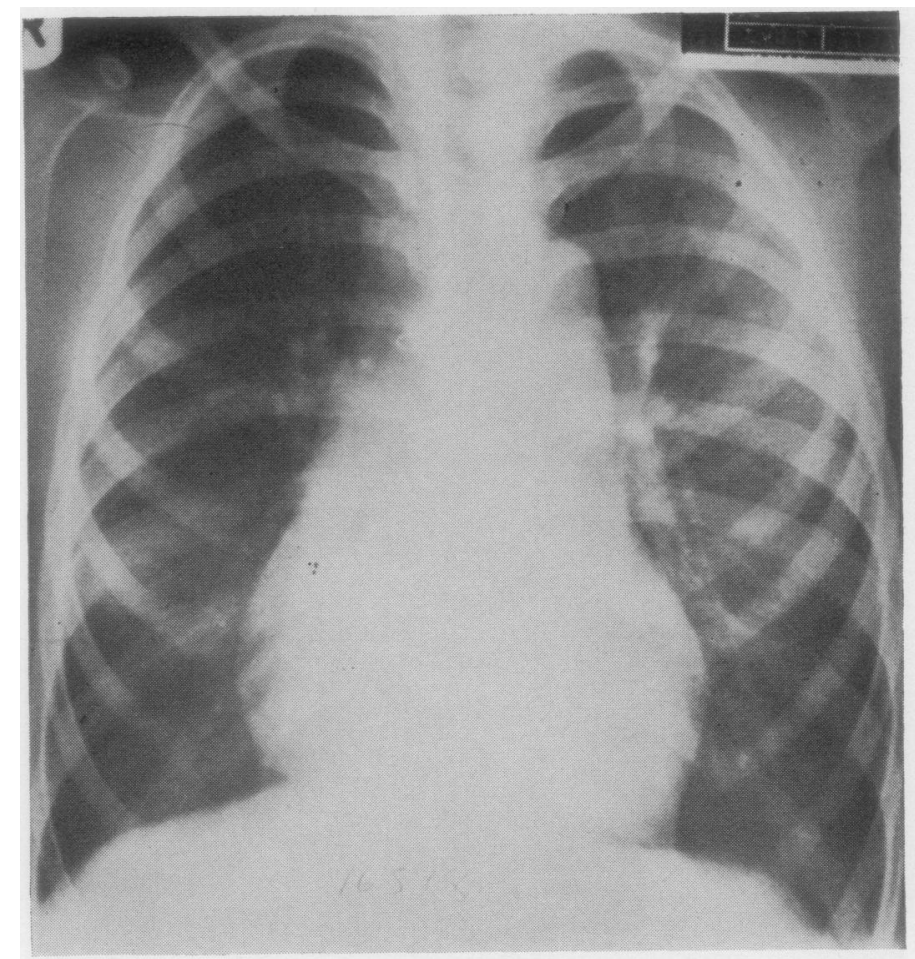

FIG. 5. Chest radiograph in May 1968, 14 months after the second operation. The heart is much smaller and the flattening of the main pulmonary artery is particularly striking. 
ECG showed sinus rhythm. Jugular venous pressure is not raised. A soft apical systolic murmur and delayed pulmonary closure sound are the only abnormal findings. He plays football and has lost all disability.

\section{DISCUSSION}

Interruption of the aortic arch is a very uncommon malformation in which there is lack of tissue continuity between the ascending and descending aorta. In its least rare form, interruption of the aortic arch forms a complex which is functionally identical with the common preductal coarctation of infancy, from which it can be distinguished only by careful angiography. This was so in our patient, who was distinguished also in surviving infancy, which is rare, even in cases of preductal coarctation.

The lower segment of the body receives blood from the right ventricle via the patent ductus arteriosus, which forms a continuous arch between the pulmonary artery and the descending aorta. Only the upper segment of the body receives blood from the ascending aorta.

Since the right ventricle supplies both the lungs and the lower segment of the body, the oxygen content and pressure in the pulmonary artery are identical with the oxygen content and pressure in the femoral artery, and the right ventricle hypertrophies. The ascending aorta is hypoplastic. The left ventricle supplies blood to both the ascending aorta and the right ventricle through a ventricular septal defect and is also enlarged. The presence of a large ventricular septal defect ensures that the pressures are identical in both ventricles and both great arteries, while a full-bore patent ductus arteriosus ensures that the pressure in the descending aorta is equal to that in the pulmonary artery and the right ventricle.

Since the resistance to flow through the lungs is usually much lower than the resistance to flow through the systemic vessels, the bulk of the right ventricular output may go to the lungs rather than to the legs. Thus the femoral artery pulses tend to be small in volume but are not delayed.

In these cases the bulk of the increased pulmonary venous return to the left ventricle passes through a big ventricular septal defect to the right ventricle. This left-to-right inter-ventricular shunt raises the level of the pulmonary artery saturation, but it must remain below the normal level of saturation in the left ventricle and the ascending aorta. Filling of the descending aorta from the pulmonary artery via the patent ductus arteriosus means that the oxygen saturation in the femoral artery is less than the oxygen saturation in the right brachial artery, but this rarely results in recognizable differential cyanosis because of the large left-to-right inter-ventricular shunt that is commonly present. If the pulmonary vascular resistance is low, there will be only a small difference between the two and no clinical differential cyanosis will be apparent. If, however, the pulmonary vascular resistance is high, then pulmonary blood flow will fall and there may be visible differential cyanosis. If the left subclavian artery and the left common carotid artery arise from the distal segment of the aorta, the left side of the face and the left arm may also be blue. If the right subclavian artery is ectopic and arises from the descending aorta, the right arm may be blue. If the great arteries are transposed, then the feet may be pink and the face and hands will be blue-so-called reversed differential cyanosis. In practice, visible differential cyanosis is rare because most of the patients are infants in failure with a high pulmonary blood flow. The generalized cyanosis of heart failure compounds the difficulty.

If (rarely) the ductus is small, as in two reported cases (Moller and Edwards, 1965), the circulation to the lower segment will be obstructed, the pressure in it will be low, and collateral vessels will develop. In such patients pulmonary blood flow tends to be further augmented by the ventricular septal defect, so that the chances of survival are even less likely.

Two patients have survived to adult life without either a patent ductus arteriosus or a ventricular septal defect (Moller and Edwards, 1965). In such patients the clinical presentation and physiology would resemble uncomplicated coarctation. The remote possibility of this major malformation provides a reason for angiography in all patients with clinical coarctation in whom the blood pressure in either arm resembles that in the legs.

In summary, when an infant or young child has heart failure with signs of a big ventricular septal defect, small or intermittently small femoral artery pulses, and especially if the feet are cyanotic, the common condition of preductal coarctation is suspected. In such babies the site of the coarctation is often difficult to identify, but the integrity of the aortic arch must be demonstrated to differentiate it from interruption of the aortic arch. In both instances injection into the right ventricle or the pulmonary artery opacifies only the descending aorta. Injection into the left ventricle via a patent foramen ovale may show the 
anatomy well enough, but more often there is simultaneous filling of the right ventricle and the pulmonary artery through a ventricular septal defect, which frequently complicates both conditions. This may obscure the ascending aorta and the arch through overlap of structures and over-dilution of the contrast. When in doubt, therefore, the contrast must be injected into the ascending aorta, which can be reached only through the right axillary artery. Otherwise it may be impossible to distinguish interruption of the aortic arch from the much commoner, but just as fatal, preductal coarctation.

Tawes, Panagopoulos, Aberdeen, Waterston, and Bonham-Carter (1969) observed that the cardiac investigation procedures were well tolerated by the infants even when they were a few days old. They also reported that the condition was diagnosed during life in 18 out of 111 reported cases and in 5 of a series of 11 cases of their own. They further reported that mortality from this malformation was high and that $95 \%$ of cases die during their first year of life. Hence they advised early exploratory thoracotomy in the hope that palliative pulmonary banding may salvage some of the cases; it may even be possible to establish continuity of the aorta and ligate or divide the patent ductus arteriosus when there is atresia of the aortic isthmus. It is of interest that in the only two living patients in their series of 11 operated cases, end-to-end anastomosis was performed between the two aortic segments and the patent ductus arteriosus was ligated. End-to-end anastomosis provided a wide lumen channel. In the other surviving patients of Ruiz Villalobos et al. (1961), Blake et al. (1962), and Pillsbury et al. (1964), a wide lumen was provided by a prosthetic vascular graft and probably accounted for the success. On the contrary, when the left subclavian artery (Tawes and associates as above, 1969) or the left common carotid artery (Quie et al., 1959) was used to bridge the gap between the aortic segments, the lumen was not wide enough, and division or ligation of the patent ductus arteriosus resulted in left heart failure and unfavourable results. In none of the above patients was the ventricular septal defect closed.

In the ingenious operation reported by Sirak et al. (1968), a wide lumen channel is constructed from the left common carotid and the left subclavian arteries for establishing continuity of the aorta. However, the risk of cerebral complications makes it less appealing.

In all these procedures one has to rely a great deal on the collateral circulation for applying the aortic clamp safely for a reasonable period to complete the anastomoses. A notable success reported by Merrill et al. (1957), in a case of atresia of the aorta between the left subclavian artery and the patent ductus arteriosus, could be largely attributed to abundant collateral circulation, which was present between the two aortic segments. Roberts et al. (1962) attributed the death in their case, after successful insertion of a Teflon graft, to the deleterious effects of aortic clamping in the absence of sufficient collateral circulation.

The institution of left heart bypass in our case provided some distinct advantages. Aortic clamping was thereby made safe. Consequently, a Teflon graft was inserted in the correct anatomical position by making a tunnel under the phrenic and the vagus nerves and the anastomoses were performed with relative ease. The importance of availability of left heart bypass cannot be overemphasized.

The underdeveloped ascending aorta may possibly present a problem after closure of the ventricular septal defect, the condition amounting to outflow obstruction of the left ventricle. The resulting left ventricular failure in our case was fortunately temporary and was successfully managed by restriction of fluid intake and administration of diuretics.

It may be anticipated that growth of the aorta may result in relative stenosis at the site of the aortic graft. So far there is no clinical indication of this (our patient is now fully grown) and there is no delay of the femoral pulses. In the future, adequate distal circulation may continue to be maintained in spite of a discrepancy between the aorta and the graft. The state of the distal circulation, however, will have to be appraised periodically.

Our thanks are due to Miss S. P. Allwork for the drawings in Fig. 1, to the Department of Medical Illustration for the photographs, and to Miss B. Allen and Miss J. Pyke for typing the paper.

\section{REFERENCES}

Abbott, M. E. (1927). Congenital cardiac disease. In Modern Medicine, ed. Osler, W., 3rd edition, Vol. 4, p. 612. Lea \& Febiger, Philadelphia.

Blake, H. A., Manion, W. C., and Spencer, F. C. (1962). Atresia or absence of the aortic isthmus. J. thorac. cardiovasc. Surg., 43,607 .

Celoria, G. C., and Patton, R. B. (1959). Congenital absence of the aortic arch. Amer. Heart J., 58, 407.

Evans, W. (1933). Congenital stenosis (coarctation), atresia, and interruption of the aortic arch (a study of twenty-eight cases). Quart. J. Med., N.S., 2, 1.

Hairston, P., Webb, H., and Lee, W. H., Jr. (1967). Aortic arch interruption; treatment with pulmonary artery bandings. J. thorac ruption; treatment with
cardiovasc. Surg., 54, 60.

Merrill, D. L., Webster, C. A., and Samson, P. C. (1957). Congenital absence of the aortic isthmus. J. thorac. Surg., 33, 311. 
Moller, J. H., and Edwards, J. E. (1965). Interruption of aortic arch; anatomic patterns and associated cardiac malformations. Amer. J. Roentgenol., 95, 557.

Pillsbury, R. C., Lower, R. R., and Shumway, N. E. (1964). Atresia of the aortic arch. Circulation, 30, 749.

Quie, P. G., Novick, R., Adams, P., Jr., Anderson, R. C., and Varco, R. L. (1959). Congenital interruption of the aortic arch. $J$. Pediat., 54, 87.

Roberts, W. C., Morrow, A. G., and Braunwald, E. (1962). Complete interruption of the aortic arch. Circulation, 26, 39.

Ruiz Villalobos, M. C., de Balderrama, D. P., Lopez y Lopez, and Castellanos, M. (1961). Complete interruption of the aorta. Amer. J. Cardiol., 8, 664.
Sirak. H. D., Ressallat, M., Hosier, D. H., and deLorimier, A. A. (1968). A new operation for repairing aortic arch atresia in
infancy: a report of three cases. Circulation, 37, suppl. 2, p. 43.

Steidele, R. J. (1777-88). Sammlg. Verschiedener in der Chirurg. prakt. Lehrschule Gemachten Beobb., Vol. 2, pp. 114-116.

Tawes, R. L., Jr., Panagopoulos, P., Aberdeen, E., Waterston, D. J., and Bonham-Carter, R. E. (1969). Aortic arch atresia and interruption of the aortic arch. $J$. thorac. cardiovasc. Surg., $58,492$.

Weisman, D., and Kesten, H. D. (1948). Absence of transverse aortic arch with defects of cardiac septums. Amer. J. Dis. Child., 76, 326. 